\title{
Modeling And Performance Analysis of A Centrifugal Impeller of Water Pump
}

\author{
V. Guru Shanker ${ }^{1}$, B. Pavan Chandu' ${ }^{2}$, K.Vijay Kumar ${ }^{3}$, Shivakumar ${ }^{4}$ \\ Assistant Professor ${ }^{1,2,3,4}$, Vignan Institute of Technology \& Science, Hyderabad, India. \\ gurushanker43@gmail.com.
}

\begin{abstract}
An impeller is a rotating component equipped with vanes or blades used in centrifugal pumps. Flow deflection at the impeller vanes allows mechanical power (energy at the vanes) to be converted into pump power output. Impeller of a centrifugal pump, usually made of iron, steel, bronze, brass, aluminum or plastic, which transfers energy from the motor that drives the pump to the fluid being pumped by accelerating the fluid outwards from the center of rotation. A significant improvement is required for impeller design to resist corrosion, Erosion \& weight less.

The present work is to design, performance of centrifugal impeller made of Poly-phenylene Sulphide (PPS) and Cast Iron materials and compared the results. Centrifugal impeller is modeled in Solid works, and that model is imported in Ansys-Software, using Ansys-Software we investigated Static and Dynamic behavior of impeller and found that the impeller with Polyphenylene Sulphide (PPS) material is best compared to Cast Iron.
\end{abstract}

Keywords - Centrifugal Impeller, Cast-Iron, polyphenylene sulphade, Corrosion resistant, Erosion Resistant.

\section{INTRODUCTION}

Centrifugal pumps are used extensively in agriculture to move water from the water source, which could be a river, dam or bore, through pipes to either a point of usage or a storage facility, such as a water tank or an irrigation system. A centrifugal pump is of a very simple design. The two main parts of the pump are the impeller and the diffuser. Impeller, which is the only moving part, is attached to a shaft and driven by a motor. An impeller is usually made of iron, steel, bronze, brass, aluminum or plastic, which transfers energy from the motor that drives the pump to the fluid being pumped by accelerating the fluid outwards from the center of rotation. A significant improvement is required for impeller design to resist corrosion, Erosion \& weight less. General Pump Impeller Failures are Failure of a bronze impeller due to a casting defect, Fragmentation of a 316 impeller due to a casting defect, Coating failure on an impeller wear ring, Pump failure due to cavitations, Wear and abrasion failure.

The main aim of this project is to analyze the impeller made of Polyphenylene Sulphide and grey cast iron. Since polyphenylene sulphide is an excellent, Corrosion and erosion resistant, Weight less, does not react with corrosive acids.

\section{Literature SURVEY}

2.1. Experimental Investigation of Thermoforming Carbon Fibre- Reinforced Polyphenylene Sulphide Composites
Mark Price et.,al (2015) [1] investigated Pre-consolidated carbon fiber reinforced polyphenylene sulphide (CF/POLYPHENYLENE SULPHIDE (PPS)) laminates were thermoformed into $\mathrm{V}$-shaped parts via designed out of autoclave thermoforming experiments. The different processing conditions tested in the experiment have resulted in final part angles whose differences ranged from 2.087 to $3.431^{\circ}$ from the original mold angle. The test results show that processing conditions influenced finished part dimensions as the final sample angles were found to decrease relative to the tooling dimensions, as mold temperature increases. Higher mold temperature conditions produce thinner parts due to the thermal expansion of mold tools. The mold temperature of $170^{\circ} \mathrm{C}$, which can produce parts with high degree of crystalline as well as small size of crystal, has been established as the optimal thermoforming condition for CF/POLYPHENYLENE SULPHIDE (PPS) composites.

\subsection{CFD Analysis Of A Mixed Flow Pump Impeller:}

A. Manivannan et.al., (2012) [4] discussed To improve the efficiency of mixed flow pump, Computational Fluid Dynamics (CFD) analysis is one of the advanced tools used in the pump industry. A detailed CFD analysis was done to predict the flow pattern inside the impeller which is an active pump component. From the results of CFD analysis, the velocity and pressure in the outlet of the impeller is predicted. CFD analyses are done using Star CCM software. The calculated value of efficiency from the empirical relations is $55 \%$. The optimum inlet and outlet vane angles are calculated for the existing impeller by using 
the empirical relations. The CAD models of the mixed flow impeller with optimum inlet and outlet angles are modeled using CAD modeling software Pro-E WF3. Three CAD models are modeled with the vane angles between existing and optimum values. These models are analyzed individually to find the performance of the impeller. In the first case, outlet angle is increased by $5^{\circ}$. From the outlet flow conditions, obtained from the CFD analysis, it is evident that the reduced outlet recirculation and flow separation cause the improved efficiency. By changing the outlet angle the efficiency of the impeller is improved to $59 \%$. In the second case inlet angle is decreased by $10 \%$. The efficiency of the impeller in this case is $61 \%$. From this analysis it is understood that the changes in the inlet vane angle did not change the efficiency of the impeller as much as the changes in outlet angle. In the third case, impeller with optimum vane angles is analyzed and the outlet flow conditions are predicted. From the CFD analysis the efficiency of the impeller with optimum vane angles is calculated as $65 \%$. Thus, efficiency of the mixed flow impeller is improved by $18.18 \%$ by changing the inlet and outlet vane angles.

\section{METHOdology}

General problems that occur in metal impeller are:

\section{Corrosion}

2. De-alloying

3. Cavitations

4. Reaction with other metals

So a material should be chosen which would overcome such defects. These defects are taken from pump impeller failure by A. VanBennekom (2014)

A. Design Calculations:

1. Flow rate, $\mathrm{Q}=0.0125 \mathrm{~m} 3 / \mathrm{s}$

2. Head, $\mathrm{H}=10 \mathrm{~m}$

3. Pump speed, $\mathrm{n}=1450 \mathrm{rpm}$

4. Gravitational acceleration, $g=9.81 \mathrm{~m} / \mathrm{s}^{2}$

5. Density of water, $\rho=1000 \mathrm{~kg} / \mathrm{m} 3$

B. Impeller Specifications:

a) Inner Diameter of impeller (D1) :0.149m

b) Outer Diameter of impeller (D2): 0.187m

c) Speed of the impeller in r.p.m : 1450

d) Vane angle at inlet : $18^{\circ}$

e) Vane angle at outlet: $37^{\circ}$

f) Number of vanes $(\mathrm{Z}): 8$

g) Design head : $10 \mathrm{~m}$

\section{DESIGN \& ANALYSIS}

The model of centrifugal impeller was made in SOLIDWORKS CAD software and then the impeller model is imported into Ansys software.

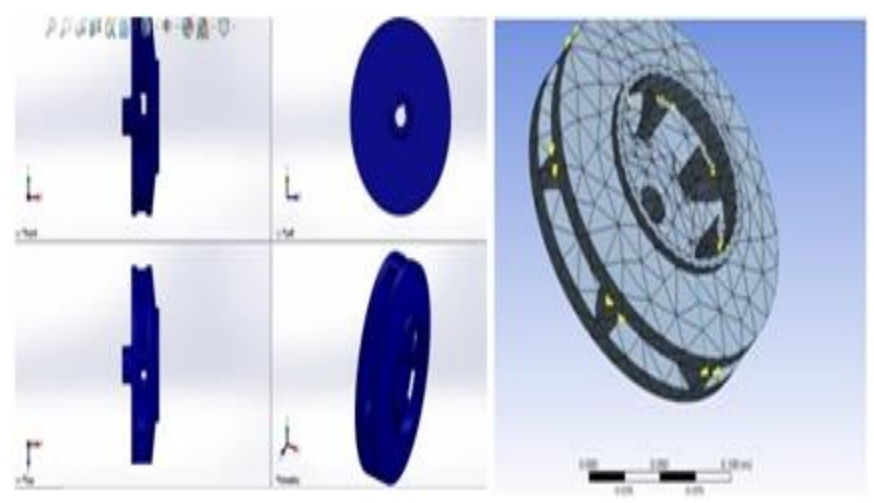

Figure.1. Modeling and Meshing of Impeller

4.1. Ansys Parameters: Locations of Boundary Conditions

i. INLET : $32465.7 \mathrm{~Pa}(0.32$ bar $)$

ii. OUTLET : $0 \mathrm{~Pa}$ (static pressure)

iii. Wheel : $1450 \mathrm{rpm}$

iv. Other walls: No slip

v. fluid water at room temperature values

4.2. Mesh Details: Apply the meshing to the impeller in order to get the nodes \& elements.

i. No of nodes: 4513

ii. No of elements: 2271

iii. Type of mesh: Tetrahedral

Analysis procedure for static structural analysis on two different materials

\subsection{Static structural analysis of Impeller:}

Structural analysis determines the displacements, stresses, strains, and forces in structures or components caused by loads that do not induce significant inertia and damping effects. Open the ANSYS workbench software, drag and drop the static structural to the create standalone system. After applying all input parameters we found the results for PPS material as shown in Table-1

Table:1. Results of Impeller with PPS material

\begin{tabular}{|l|c|c|c|}
\hline Type & $\begin{array}{l}\text { Total } \\
\text { Deformation } \\
\text { In }(\mathrm{mm})\end{array}$ & $\begin{array}{c}\text { Equivalent } \\
\text { Elastic Strain }\end{array}$ & $\begin{array}{c}\text { Von-Mises } \\
\text { Stress, in } \\
(\mathrm{MPa})\end{array}$ \\
\hline Minimum & 0 & $1.8302 \mathrm{e}-006$ & $4.4929 \mathrm{e}-003$ \\
\hline Maximum & $3.6878 \mathrm{e}-003$ & $1.1061 \mathrm{e}-004$ & 0.43889 \\
\hline Average & $2.0175 \mathrm{e}-003$ & $3.5366 \mathrm{e}-005$ & 0.1291 \\
\hline
\end{tabular}




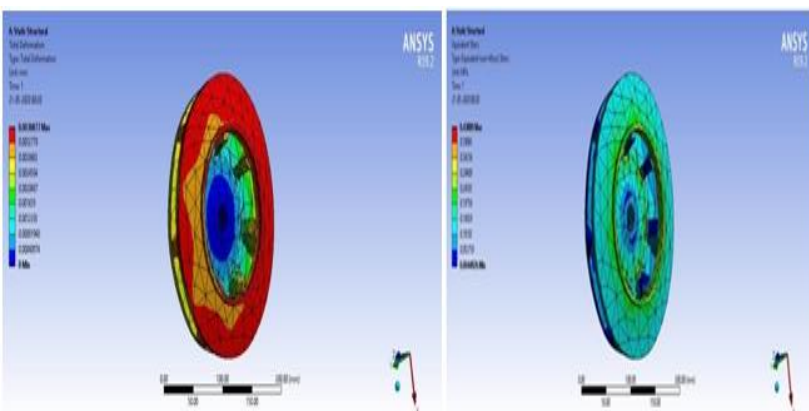

Figure.2.a. Total Deformation \& 2.b. Von-mises Stress of PPS Material

The figure-2.a. Shows the PPS Material minimum deformation value is zero at eye of the impeller (blue color), maximum deformation value is $3.6878 \mathrm{e}-003 \mathrm{~mm}$ at outer casing of the impeller (red color).

Figure-2.b. shows the PPS Material von-mises stress, the minimum value is $4.4929 \mathrm{e}-003 \mathrm{MPa}$ and maximum value is $0.43889 \mathrm{MPa}$

\begin{tabular}{|l|c|c|c|}
\hline Type & $\begin{array}{c}\text { Total } \\
\text { Deformation In } \\
(\mathrm{mm})\end{array}$ & $\begin{array}{c}\text { Equivalent Elastic } \\
\text { Strain }\end{array}$ & $\begin{array}{c}\text { Von-Mises } \\
\text { Stress, in } \\
(\mathrm{MPa})\end{array}$ \\
\hline Min. & 0 & $3.3879 \mathrm{e}-$ & $1.9733 \mathrm{e}-$ \\
& 007 & 002 \\
\hline Max. & $\begin{array}{c}7.1519 \mathrm{e}- \\
004\end{array}$ & $\begin{array}{c}2.1506 \mathrm{e}- \\
005\end{array}$ & 2.3469 \\
\hline Avg. & $\begin{array}{c}3.9181 \mathrm{e}- \\
004\end{array}$ & $6.863 \mathrm{e}-$ & 0.68841 \\
& 006 & \\
\hline
\end{tabular}

Table: 2 Results of Impeller with Cast-Iron material

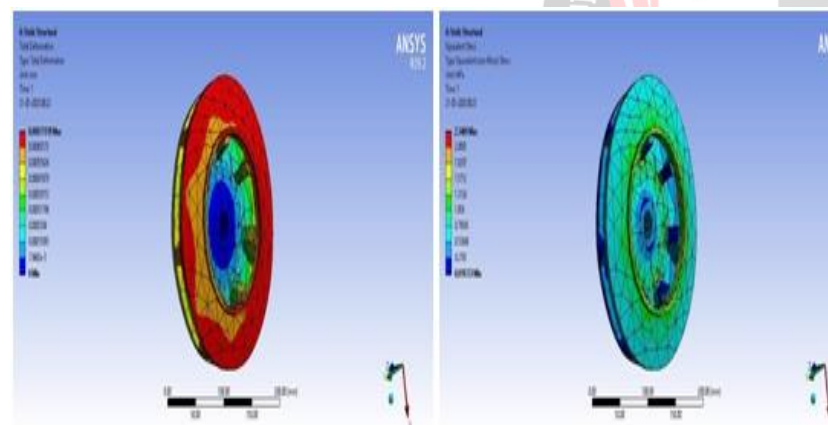

Figure.3.a. Total Deformation \& 3.b. Von-mises Stress of Cast-Iron Material

The figure-3.a. Shows the Cast-iron material minimum deformation value is zero at eye of the impeller (blue color), maximum deformation value is $7.1519 \mathrm{e}-004 \mathrm{~mm}$ at outer casing of the impeller (red color).

Figure-3.b. shows the Cast-iron material von-mises stress, the minimum value is $1.9733 \mathrm{e}-002 \mathrm{MPa}$ and maximum value is $2.3469 \mathrm{MPa}$.

\subsection{Model Analysis of Impeller:}

Six modes shapes and a fixed support is applied on Centrifugal Impeller
Graph.1. Model Analysis on Impeller with PPS Material

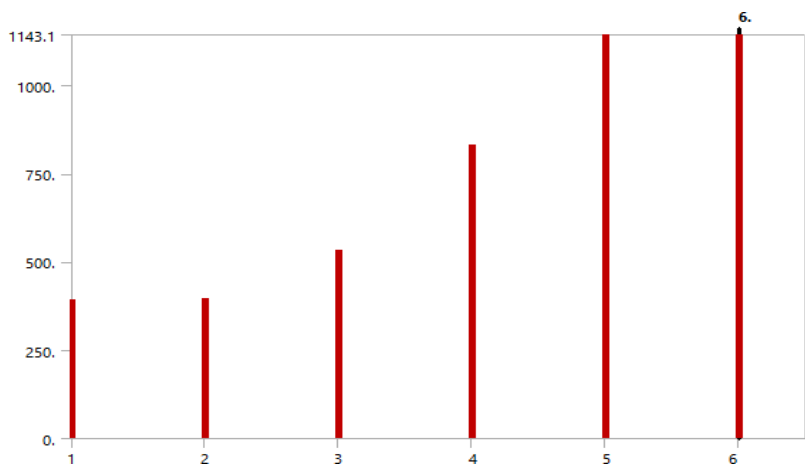

The graph.1. Describes the different mode shapes of the impeller with deformations and the frequencies as shown in Table.3.

Table: 3. Results of Impeller with PPS material:

\begin{tabular}{|c|c|c|}
\hline Mode & $\begin{array}{c}\text { Total Deformation, in } \\
(\mathrm{mm})\end{array}$ & $\begin{array}{c}\text { Frequency, in ( } \\
\text { Hz) }\end{array}$ \\
\hline 1 & 26.3 & 392.98 \\
\hline 2 & 25.089 & 397.91 \\
\hline 3 & 27.54 & 531.68 \\
\hline 4 & 28.77 & 830.05 \\
\hline 5 & 25.74 & 1141.5 \\
\hline 6 & 25.45 & 1143.1 \\
\hline
\end{tabular}

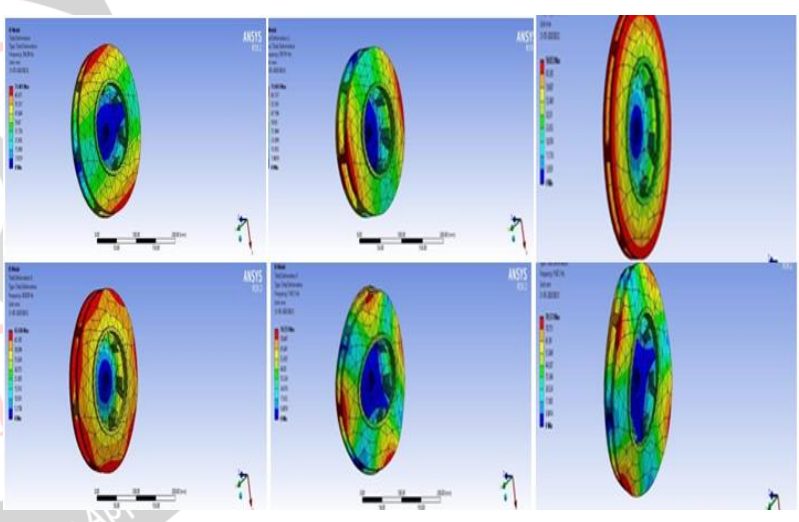

Figure.4. Deformation of impeller at different Modes for PPS material
The figure-4. Shows the PPS Material of deformation at various mode shapes and it is found that deformation is maximum at mode- 1 and minimum at mode- 6 .

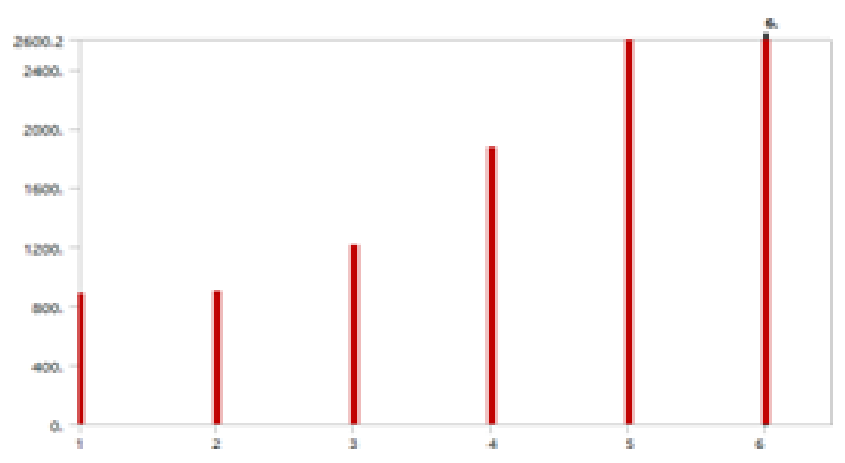

Graph.2. Model Analysis on Impeller with Cast-Iron Material 
The graph.2. Describes the different mode shapes of the impeller with deformations and the frequencies as shown in Table.4.

Table:4. Results of Impeller with Cast-Iron:

\begin{tabular}{|l|l|l|}
\hline Mode & Total Deformation, in $(\mathrm{mm})$ & Frequency, in $(\mathrm{Hz})$ \\
\hline 1 & 30.92 & 887.92 \\
\hline 2 & 31.05 & 899.18 \\
\hline 3 & 22.07 & 1215.4 \\
\hline 4 & 20.51 & 1875.6 \\
\hline 5 & 34.205 & 2596.3 \\
\hline 6 & 34.392 & 2600.2 \\
\hline
\end{tabular}
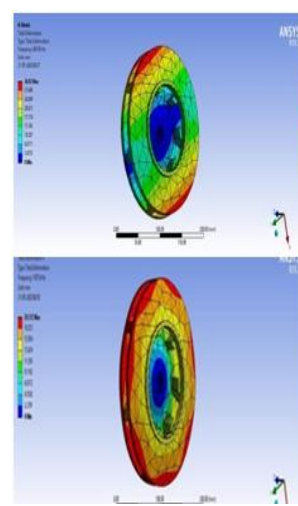
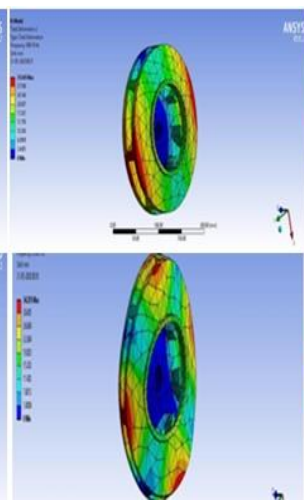

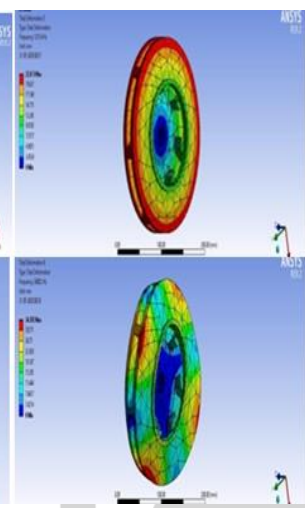

Figure.5. Deformation of impeller at different $\overline{\text { Modes for }}$

The figure-5. Shows the Cast Iron Material of deformation at various mode shapes and it is found that deformation is maximum at mode- 6 and minimum at mode- 4 .

\section{Results}

The minimum and maximum values of total deformation of PPS material is $0 \& 0.00 \mathrm{E}+00$ and $7.15 \mathrm{E}-04 \& 3.69 \mathrm{E}-03$ which is sight equal to the cast iron, as shown in Graph.3.

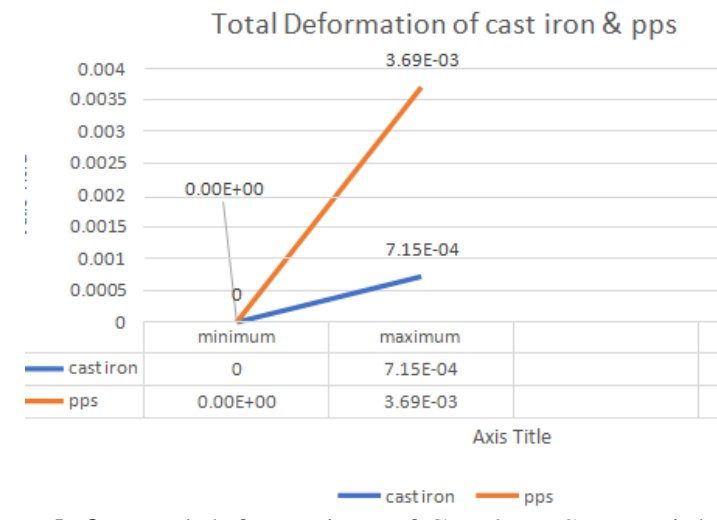

Graph.3. Total deformation of C.I. \& PPS Material
The minimum and maximum values of stresses of PPS material is 4.49E-03 \& 0.43889 and 1.97E-02 \& 2.3469, which is less than to the cast iron, as shown in Graph.4.

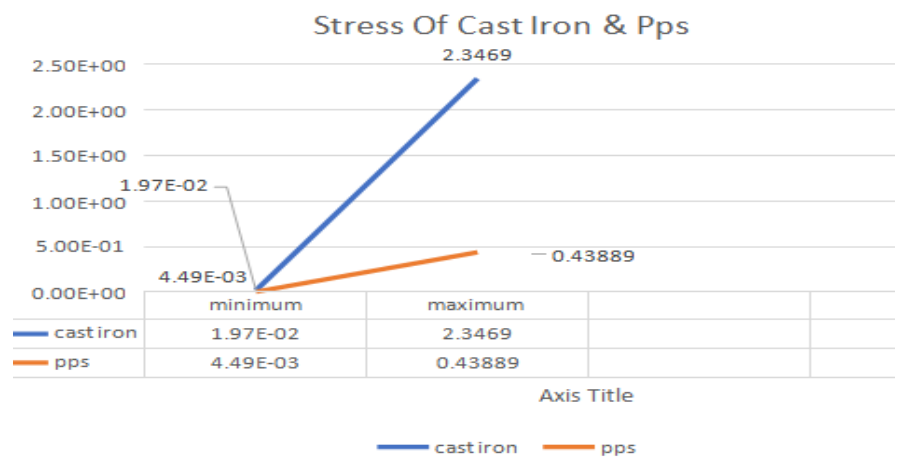

Graph.4. Stress of C.I. \& PPS Material

Modal Analysis results of cast iron \& PPS with 6 mode shapes are deformation of cast iron is minimum at mode- 6 and for PPS Material is minimum at mode-1, as shown in Graph.5.

AVERAGE RESULTS OF DEFORMATIONS OCCURS IN NATURAL FREQUENCY

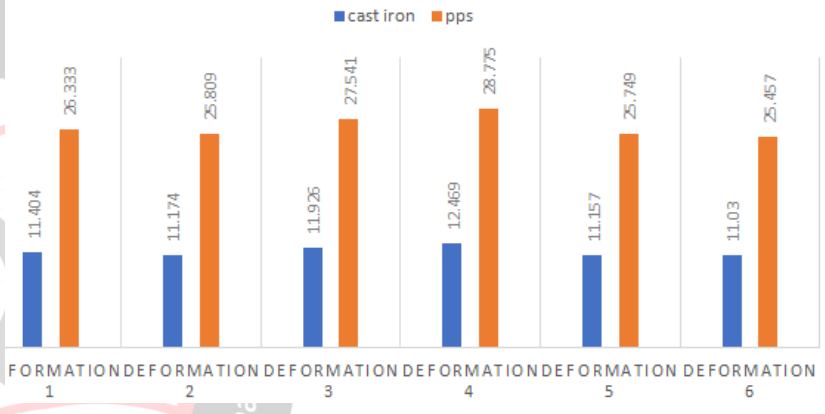

Graph.5. Model Analysis of Cast-Iron \& PPS Material.

\section{CONCLUSION}

Thus the centrifugal impeller is modeled and analyzed and it is found that the stresses are slightly less in case of polyphenylene sulphide (PPS) Material when compared to cast iron. Even deformation slightly higher with polyphenylene sulphide (PPS) can be used in applications ranging less than 0.3 bar. So the applications are used for solar water pumping system for small scale irrigation purpose.

\section{Scope For Further Study:}

In future the same polyphenylene sulphide material which is also available as glass fiber and bearing grade material can also be analyzed on the basis of their properties and also varying the design of blade angles which may give a better result than what is obtained now.

\section{REFERENCES}

[1]. Mark Price et.,al,"Experimental Investigation of Thermoforming Carbon Fibre-Reinforced Polyphenylene Sulphide Composites", An open paper from Google Scholar, 2015. 
[2]. Jianjun Lu et.al.,"Performances \& Structure Changes of Neat Polyphenylene sulphide (pps) \& Ti-Sio2-Modified Polyphenylene sulphide (pps) After Over Temperature Oxidation", an open paper from Google Scholar, 2014.

[3]. Dandan Lian et.al.,"Effect Of Ti-Sio2 Nanoparticles on Non Isothermal Crystallazation Of Polyphenylene Sulfide" an open paper from Google Scholar, 2014. A. Manivannan et.al.,"CFD Analysis of a Mixed Flow Pump Impeller", An open paper from Google Scholar, 2012.

[4]. Mario Saver et.al.,"Improving Centrifugal Pump Efficiency By Impeller Trimming", An open paper from Google Scholar, 2008.

[5]. Fan Aiming, et.al.,"Failure Analysis of the Impeller of a Slurry Pump Subjected to Corrosive Wear", An open paper from Google Scholar, 2005.

[6]. S. Ariely, et.al.,"Erosion Corrosion of Pump Impeller of Cyclic Cooling Water System", An open paper from Google Scholar, 2004.

[7]. Perez J, Chiva S et.al.,"Performance Analysis Of Flow In An Impeller-Diffuser Centrifugal Pumps Using Cfd: Simulation And Experimental Data Comparisons", An open paper from Google Scholar, 2010.

[8]. Khin Cho Thin, MyaMyaKhaing, KhinMaung Aye, "Design and Performance Analysis of Centrifugal Pump", World Academy of Science, Engineering and Technology, pp. 46, 2008. 